\title{
$\beta$-Carotene colouring systems based on solid lipid particles produced by hot melt dispersion
}

\author{
Amarilis Santos de Carvalho ${ }^{\mathrm{a}, \mathrm{b}}$, Stephany Cunha de Rezende ${ }^{\mathrm{a}}$, Cristina Caleja ${ }^{\mathrm{a}}$, Eliana Pereira ${ }^{\mathrm{a}}$, \\ Lillian Barros $^{\mathrm{a}, *}$, Isabel Fernandes ${ }^{\mathrm{a}}$, Yaidelin A. Manrique ${ }^{\mathrm{c}}$, Odinei Hess Gonçalves ${ }^{\mathrm{a}, \mathrm{b}}$, Isabel C. \\ F.R. Ferreira ${ }^{a}$, Maria Filomena Barreiro ${ }^{\text {a, } * *}$ \\ ${ }^{a}$ Centro de Investigação de Montanha (CIMO), Instituto Politécnico de Bragança, Campus de Santa Apolónia, 5300-253, Bragança, Portugal \\ ${ }^{\mathrm{b}}$ Post-Graduation Program of Food Technology (PPGTA), Federal University of Technology - Paraná - UTFPR, Campus Campo Mourão, Via Rosalina Maria Dos Santos, \\ 1233, CEP 87301-899, Caixa Postal: 271, Campo Mourão, PR, Brazil \\ ${ }^{\mathrm{c}}$ Laboratory of Separation and Reaction Engineering - Laboratory of Catalysis and Materials (LSRE-LCM), Faculdade de Engenharia, Universidade Do Porto, Rua Dr. \\ Roberto Frias, 4200-465 Porto, Portugal
}

\section{A R T I C L E I N F O}

\section{Keywords:}

Natural colourants

Stabilisation

Solid lipid particles

Hot melt dispersions

Food applications

\begin{abstract}
A B S T R A C T
In this work, $\beta$-carotene was selected to develop a novel study, namely a food colorant system based on beeswax solid lipid particles obtained by hot melt dispersion. The obtained microparticles were characterized by optical microscopy, scanning electron microscopy, particle size analysis and Fourier Transform Infrared spectroscopy. It was observed that the obtained size can be modulated by using different amounts of emulsifier, as well as the dispersing capability. In a final stage, the obtained particles were tested concerning their colorant power by selecting a food matrix widely appreciated and consumed (mayonnaise). Moreover, the formulation providing the best hue and dispersibility (formulation containing $3 \%$ of Tween 80 , and $\beta$-carotene at $5 \mathrm{mg} / 25 \mathrm{~g}$ of commercial mayonnaise) was analysed along a storage period of 15 days concerning colour, nutritional value and chemical composition. The results pointed out for colour stability and nutritional value maintenance, after 15 days under storage at $6^{\circ} \mathrm{C}$.
\end{abstract}

\section{Introduction}

In the food industry, most of the used additives have synthetic origin. However, in the recent decades, consumer' awareness concerning potential harmful effects of these compounds and the search for a healthier lifestyle, leaded to an increased consumption of equivalent-functional natural ingredients (Carocho, Barreiro, Morales, \& Ferreira, 2014).

The colourants of natural origin include different families of pigments, some of them belonging to the carotenoids group, namely the $\beta$-carotenes (for example, bixins, norbixin, and lutein) and lycopenes (luteins such as xanthophyll and canthaxanthin, among others) (Msagati, 2013). $\beta$-carotene, in addition to its natural origin, can be chemically synthesised and is classified as "identical to natural", being widely used in the food sector. Additionally, among the 50 different carotenoids that can be metabolised to vitamin A, $\beta$-carotene shows a high pro-vitamin A activity (Krinsky \& Johnson, 2005). Therapeutically, there are strong evidences suggesting that a diet rich in fruits and vegetables containing $\beta$-carotene can be related to cancer risk reduction, mainly lung cancer (Lim \& Wang, 2020). This molecule has a chemical structure comprising double bonds highly conjugated with a symmetry centre, which configures its high hydrophobic character. The highly conjugated polyene structure is responsible for the yellow and orange hue, due to the absorption of light in the visible region (Kohno et al., 2016). Despite their hydrophobic nature, conjugated bonds are reactive and therefore $\beta$-carotene is not very resistant to oxidation. Namely, in the presence of other compounds containing conjugated double bonds, and when exposed to air, particularly in the presence of light, it undergoes oxidative degradation resulting in a quick colour loss. Due to this instability, its effective use as a colorant agent, namely in food products, will benefit from the adoption of stabilisation procedures (Kohno et al., 2016). Several techniques can be used for the stabilisation and protection of these pigmented compounds; among them,

\footnotetext{
* Corresponding author.

$* *$ Corresponding author.

E-mail addresses: lillian@ipb.pt (L. Barros), barreiro@ipb.pt (M.F. Barreiro).
} 
encapsulation stands out as one of the most preferable and effective methods, especially when natural polymers are employed as carriers (Azeredo, 2005; de Boer et al., 2019). Among several possibilities, solid lipid particles (SLPs) have recently emerged in the food industry as an approach for encapsulating bioactive substances, as an attempt to offer protection against instability to external factors (Gordillo-Galeano \& Mora-Huertas, 2018; Santos et al., 2019). Several methods can be used for the production of SLPs with the most relevant ones being spray-congealing, melt solidification, and melt dispersion, where the homogenization/dispersion step can be achieved through conventional techniques like high-pressure homogenization, high shear homogenization, ultrasonication, membrane emulsification, among others (Ganesan \& Narayanasamy, 2017; Schjoerring-Thyssen et al., 2019; Zhong \& Zhang, 2019).

To produce SLPs, the choice of the technique to be used is mostly dependent on the physicochemical properties of both encapsulated and encapsulant compounds, as well as of the final product' target properties (Kamble et al., 2004). As examples of encapsulant materials, triglycerides, sterols, fatty acids, waxes, and lipid derivatives can be used (Ghanbarzadeh \& Keivani, 2019). Waxes use are being extensively reported in recent works due to their excellent stability to external conditions ( $\mathrm{pH}$, temperature, and moisture), besides being safe for food use (Campos et al., 2020).

Regarding the application areas of SLPs, pharmaceutical and cosmetic are the most referred ones in the available literature, while studies targeting the food area are limited. In this last case, most of the studies are related with the encapsulation of lipophilic bioactive compounds, enzymes and probiotics (Zhong \& Zhang, 2019). Therefore, only few works devoted to the use of this technique for natural colorants encapsulation, aiming at protecting the colour against external factors, and thus enhance their applicability have been reported. In particular, the encapsulation of $\beta$-carotene in solid lipid particles has been reported to increase its stability against oxidative and thermal degradation (Mehrad et al., 2018; Schjoerring-Thyssen, 2019; Selvakumar et al., 2019; Salminen et al., 2020). The incorporation of SLPs containing $\beta$-carotene in complex food matrices (e.g. ice cream, margarine, mayonnaise, chocolates, etc.), and the evaluation of their performance in these systems, even also addressed it is still limited (de Lima et al., 2016; Santos et al., 2019), putting in evidence the importance and novelty of the present work."

This work aims to develop a colorant system based on $\beta$-carotene for food applications. To achieve this goal, beeswax-based solid lipid particles produced by hot-melt dispersion were chosen as the carrier. The obtained particles were thoroughly characterized (OM - optical microscopy, SEM - scanning electron microscopy, FTIR - Fourier-transform infrared spectroscopy, and particle size analysis), and their colorant performance tested by incorporation into a widely appreciated and consumed food product, mayonnaise, by evaluating its stability along a storage period of 15 days. The selection of a food matrix based on an oilin-water emulsion such as mayonnaise, is due to its high compatibility with the wax-based particles together with the benefits of colour intensification due to $\beta$-carotene incorporation.

The incorporation tested in this work, namely the use of $\beta$-carotene loaded lipid particles as a colorant system, brings novelty to the present state of the art since taking into account the available literature, no studies dealing with the inclusion of colouring ingredients based on $\beta$-carotene in mayonnaise were found. The present study will bring innovation to the scientific community, and also development to the food sector, offering to consumers healthier food alternatives.

\section{Materials and methods}

\subsection{Materials}

$\beta$-carotene was acquired from Sigma-Aldrich (St. Louis, MO, USA). Beeswax, the lipid encapsulant, was purchased from Acros Organics
(Geel, Belgium). The emulsifier (Tween 80 ) was provided by Panreac Quimica S.L.U (Barcelona, Spain). Mayonnaise, the chosen lipophilic food matrix for the application test was purchased from a local supermarket. Its composition comprised $80 \%$ of rapeseed oil, $6 \%$ of pasteurized egg yolk, and other compounds (alcohol vinegar, sugar, mustard seed salt, citric acid and disodium calcium EDTA). For the nutritional and chemical analysis (control mayonnaise and developed mixtures), acetonitrile (99.9\%), n-hexane (95\%), absolute ethanol (99.9\%) and ethyl acetate (99.8\%) were used, all of HPLC-grade and purchased from Fisher Scientific (Lisbon, Portugal). Water was treated through a Milli-Q purification system (TGI Pure Water Systems, Greenville, SC, USA).

\subsection{Particles obtainment by hot melt dispersion}

The particles were obtained by the hot melt dispersion method following a procedure described in the literature (Gowda \& Shivakumar, 2007; Kamble et al., 2004; Milanović et al., 2017; Paradkar et al., 2003) with some adaptations. The procedure was carried out using an experimental setup comprising a mechanical stirrer (Eurostar 40 model, IKA ${ }^{\circledR}$ ) equipped with a propeller type impeller, and a heating system consisting of a heating plate equipped with a thermocouple (602/6 model, NAHITA) to control the oil bath temperature. Briefly, the lipid phase, beeswax, was firstly melted at $90{ }^{\circ} \mathrm{C}(10 \mathrm{~g})$ followed by the dissolution of $\beta$-carotene $(0.12 \mathrm{~g})$ under stirring. Tween $80(0,0.5,1$, and $3 \%, \mathrm{w} / \mathrm{w}$, total volume-basis) was solubilized in water $(70 \mathrm{~mL})$ at $90^{\circ} \mathrm{C}$. Then, the lipid phase was dropped to the aqueous phase under constant stirring $(2000 \mathrm{rpm}, 20 \mathrm{~min}$ ) to achieve the reduction of the particle size of the dispersion. Thereafter, the dispersion was submitted to a rapid cooling by using an ice bath to promote the consolidation of the solid particles. In the final step, the particles were recovered by decantation using an ampoule followed by washing with distilled water. The obtained particles were thereafter stored in a desiccator until use.

\subsection{Particles characterization}

\subsubsection{Morphological analysis}

Morphological analysis of the formed microparticles was performed by optical microscopy (OM) and scanning electron microscopy (SEM). OM analysis was carried out with a microscope Nikon model Eclipse 50i (Amsterdam, Netherlands). For SEM, images were acquired using a desktop scanning electron microscope Phenom Pro (Thermo Fisher Scientific, Dillenburgstraat, Netherlands) equipped with backscattered electron detector. The sample analysis was done without sputter coating application, using the charge reduction mode and the low vacuum sample holder, under an acceleration voltage of $15 \mathrm{kV}$. For OM, a drop of the reactive mixture sampled right after the production was collected and analysed. For SEM, the recovered samples after decantation and washing were stored in a desiccator until characterization.

\subsubsection{Laser diffraction $(L D)$}

Particle size distributions were determined by laser diffraction (LD) using a Malvern Mastersizer 3000 (Malvern, United Kingdom) using distilled water as the dispersant medium. The evaluated parameters were D10, D50 and D90, in volume, which indicated the particle size corresponding to 10,50 and $90 \%$ of the total volume of the particles in the sample. The evaluated samples correspond to the ones recovered after decantation and washing.

\subsubsection{Fourier-transform infrared spectroscopy (FTIR)}

FTIR analysis was carried out using a MB300 FTIR from ABB (Zurich, Switzerland) operating in attenuated total reflectance (ATR) mode using a cell equipped with a diamond crystal. The following parameters were used: $32 \mathrm{scans} / \mathrm{min}$, a resolution of $16 \mathrm{~cm}^{-1}$ and a reading range of 4000 to $500 \mathrm{~cm}^{-1}$. Spectra were acquired and treated with Horizon MB version 3.4 software. For the analysis, a sample of each product (liquid or powder) was placed directly on the crystal surface. Thereafter the 
ATR cell was closed before starting the analysis. The spectra of the base materials (beeswax, Tween 80, $\beta$-carotene) and of the formed microparticles were acquired.

\subsection{Incorporation of particles produced in commercial mayonnaise}

The incorporation was done by using the produced beeswax microparticles and $\beta$-carotene alone. The calculated amount of lipid particles considered an equivalent amount of the corresponding free form of $\beta$-carotene. Thus, 16 samples of mayonnaise $(25 \mathrm{~g})$ were prepared, 3 with pure $\beta$-carotene $(1.25,5$, and $10 \mathrm{mg}), 12$ (3 for each formulation $(0$, $0.5,1$, and $3 \%$ of surfactant)) using the produced microparticles (104, 416, and $832 \mathrm{mg}$ ), and 1 without any addition (control sample). In all cases, the limits established by the legislation of acceptable $\beta$-carotene daily dose were respected (acceptable daily intake (ADI) of $0-5 \mathrm{mg} / \mathrm{kg}$ body weight/day (EFSA, 2012)).

\subsection{Evaluation of colour parameters}

The sample colour was measured using a colourimeter (model CR400, Konica Minolta Sensing Inc., Tokyo, Japan). The illuminate C, and a diaphragm aperture of $8 \mathrm{~mm}$ previously calibrated against a standard white tile were used. The CIE $L^{*}$ (lightness), $a^{*}$ (greenness/ redness), and $b^{*}$ (blueness/yellowness) colour space values were registered using the data software "Spectra Magic Nx" (version CM-S100W 2.03.0006) (Caleja et al., 2016). For the sample showing the best colour and dispersibility characteristics, the colour performance was evaluated over two pre-defined shelf-life times: right after incorporation (T0 days) and after 15 days under storage in the refrigerator at $6^{\circ} \mathrm{C}(\mathrm{T} 15$ days). The storage times have been defined according to the indications present in the product's label, namely the recommended storage time after opening.

\subsection{Nutritional characterization}

Nutritional characterization was performed for the sample showing the best colour and dispersibility characteristics at times T0 and T15. The results were compared against a control sample (sample without adding the colouring particles).

The contents of protein, fat, carbohydrates and ash, were determined according to the AOAC methods (AOAC International, 2016) and following the methodology previously reported by Barros et al. (2013). The total carbohydrates were obtained by difference, and the energy value calculated using the equation: Energy $(\mathrm{kcal})=4 \times(\mathrm{g}$ protein $+\mathrm{g}$ carbohydrates $)+9 \times(\mathrm{g}$ fat $)$.

\subsection{Chemical composition}

Free sugars were isolated by extraction and evaluated according to a procedure previously described by Barros et al. (2013). After the extraction, the samples were filtered through a $0.2 \mu \mathrm{m}$ Whatman nylon filters into a $1.5 \mathrm{~mL}$ vial for analysis by liquid chromatography (HPLC, Knauer, Smartline 1000 systems, Berlin, Germany), coupled with a refractive index detector (Knauer Smartline 2300). The detected compounds were identified by comparison with the retention times of authentic standards (D(-)-fructose, $\mathrm{D}(+)$-sucrose, $\mathrm{D}(+)$-glucose, $\mathrm{D}$ $(+)$-trehalose and $\mathrm{D}(+)$-raffinose pentahydrate, Sigma-Aldrich, St. Louis, MO, USA). Melezitose was used as the internal standard in the quantification method. The results were expressed in $\mathrm{g} / 100 \mathrm{~g}$ of dry weight (dw).

The fatty acids were evaluated according to a methodology previously described by Barros et al. (2013). The determination was performed through gas chromatography coupled with a flame ionisation detector (GC-FID, DANI model GC 1000, Contone, Switzerland). Identification was achieved by comparison with relative retention times of the commercial fatty acid methyl ester mixture (FAME standard
47885-U, Sigma-Aldrich, St. Louis, MO, USA) standard peaks. The results were expressed as a relative percentage (\%). Similarly to the nutritional evaluation, chemical composition was performed for the sample showing a best colour and dispersibility characteristics, at T0 and T15.

\subsection{Statistical analysis}

All the assays were performed in triplicate, and the results are expressed as mean \pm standard deviation (SD). The collected data was analysed using the ANOVA test, to determine the significant differences between the four samples (control T0, control 15, mixture T0 and mixture T15), with $p$-value $=0.05$ (SPSS v. 23.0; IBM Corp., Armonk, New York, USA).

\section{Results and discussion}

\subsection{Morphological analysis of the microparticles}

Fig. 1 shows the images acquired by OM and SEM for the four produced formulations $(0,0.5,1$, and $3 \%(w / w)$ of surfactant). From the $\mathrm{OM}$ images (images acquired right after production) it can be observed that the size of the particles decreases substantially when the emulsifier is added. Thereafter, it decreases as the emulsifier content increases, achieving the lowest size for the surfactant content of $3 \%$ (Fig. 1D). This behaviour is related with the emulsifier role that promotes the lowering of the surface tension at the liquid lipid water interface, enabling the reduction of the lipid droplets size during the particle's production (Ban et al. 2018, 2020). By SEM analysis it is possible to observe the spherical shape of particles, but also an heterogenous size distribution, as well as signs of agglomeration, characteristic that can be attributed to the drying stage of the samples. The heterogeneous size distribution is directly associated with the used preparation conditions, namely the stirring rate and time (Milanovic et al., 2011). Uniform sizes are usually generated when a high stirring rate is employed. Costa et al. (2020) obtained SLPs with higher size homogeneity when using a stirring rate of $5000 \mathrm{rpm}$, in comparison with other formulations using lower rates. According to literature (Eldem et al., 1991; Ishimoto et al., 2019), the action of the emulsifier benefits the dispersibility in water, besides contributing to achieve particles with higher homogeneity in size. For the particles where no emulsifier was added (Fig. 1A), a larger size, but particularly a highly pronounced agglomeration was observed, hindering further dispersion in the target products. As the amount of emulsifier increases, the particles appear to be more individualized, presenting also a more defined spherical shape (detected by SEM, which translates the drying state). From the preformed analysis it is expected that the sample produced with the higher amount of emulsifier will present the best dispersibility characteristics.

\subsubsection{Particle size analysis}

Fig. 2 represent the particle size distribution in volume with the respective D10, D50 and D90 values. In a general way, distributions in volume are multimodal, as it is the present case. The average particle size (D50 value) in volume indicates a decrease size pattern as the emulsifier content increases from 0 to $3 \%$. Namely, the higher value $(344 \mu \mathrm{m})$ was obtained for the sample produced without emulsifier, while the smallest one $(10.80 \mu \mathrm{m})$, was obtained for the sample using $3 \%$. As expected, these results point out a decrease in the size of the particles as Tween 80 content increased, corroborating the previously described in the morphological analysis. The increase in the emulsifier content facilitates the formation of small droplets during the dispersion phase (Kheradmandnia et al., 2010), leading to small size lipid particles.

\subsubsection{FTIR analysis}

Fig. 3 presents the FTIR spectra of the used base materials to produce the particles (beewax, Tween 80 , and $\beta$-carotene), together with the 


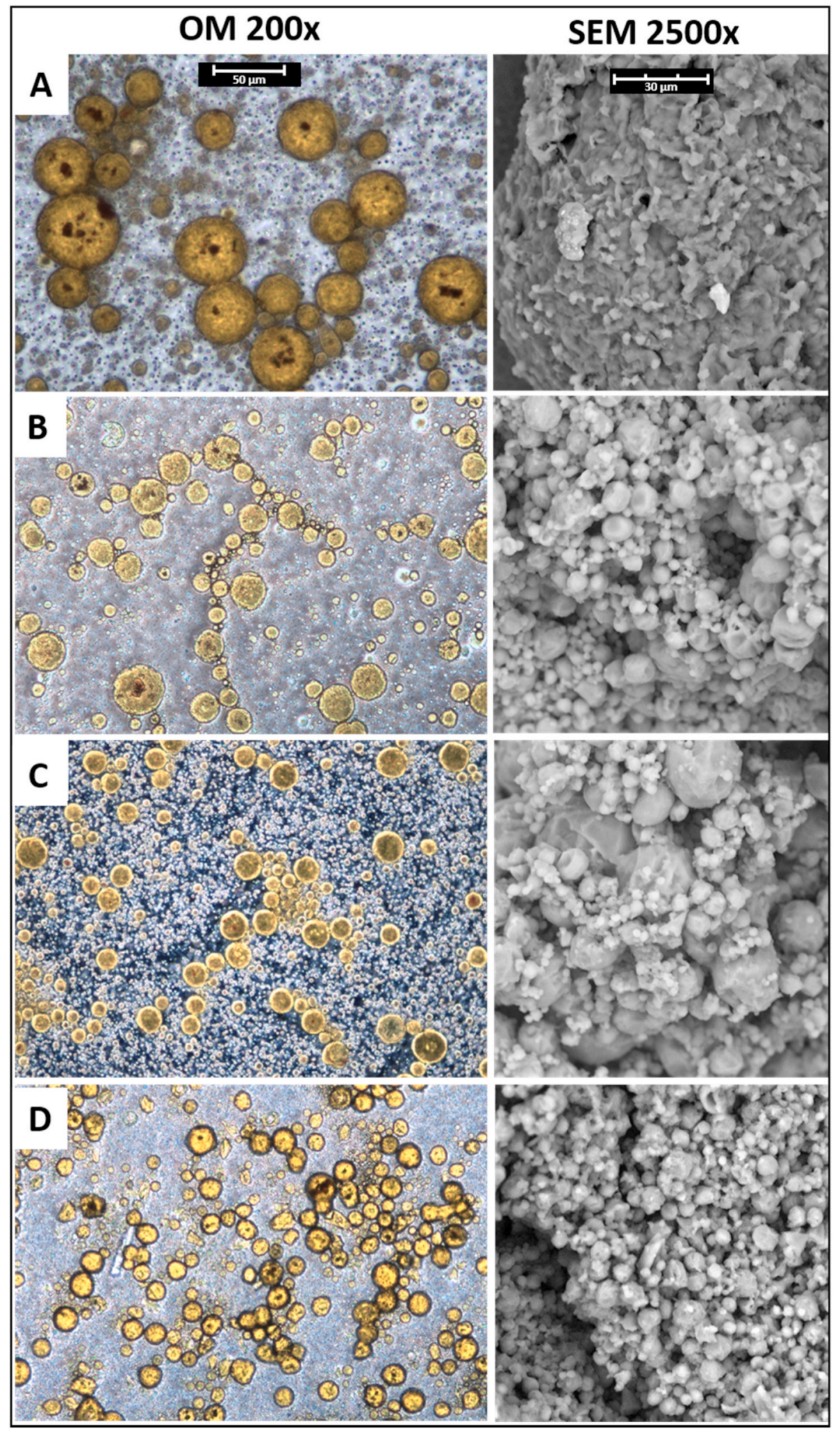

Fig. 1. Optical microscopy (OM, before drying) (200x) and scanning electron microscopy (SEM, after drying) (2500x) of particles. (A) $0.0 \%$, (B) $0.5 \%$, (C) $1.0 \%$ and (D) $3.0 \%$.

spectra of the produced solid lipid particles. In order to better evaluate the impact of beeswax, Tween 80 and $\beta$-carotene, in the produced particles, a magnification of the spectra obtained for the produced lipid particles was done in the region $1700-700 \mathrm{~cm}-1$. Concerning the spectra obtained for pure components, Tween 80 presented peaks at $3433 \mathrm{~cm}-1$ characteristic of hydroxyl (OH) groups; vibrations at 2920 and $2860 \mathrm{~cm}$ 1 associated with $\mathrm{CH} 2$ groups, and at $1737 \mathrm{~cm}-1$ related with the carbonyl $(\mathrm{C}=\mathrm{O})$ group. The most characteristic peak located at 1099 $\mathrm{cm}-1$ is associated with the ester vibration (-COO-). The same assignments were reported by Liu et al. (2015). For $\beta$-carotene, the primary 


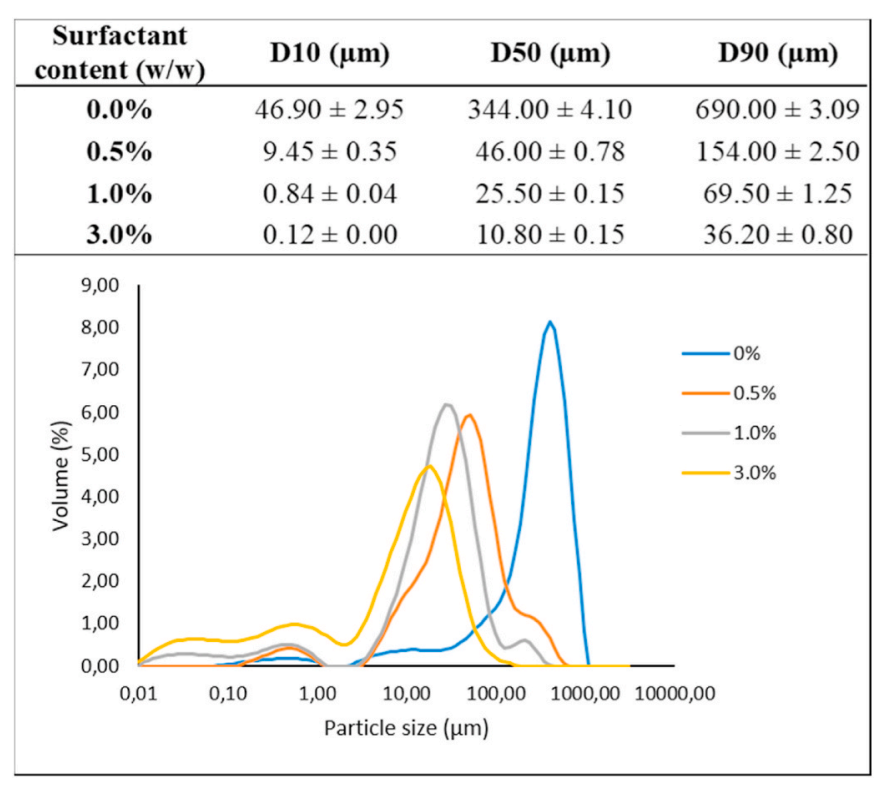

Fig. 2. Particle size distribution in volume (D10, D50 and D90) for the produced microparticles $(0.0 ; 0.5 ; 1.0$, and $3 \%$ Tween 80$)$.

vibrations identified at 2914 and $1361 \mathrm{~cm}^{-1}$ are associated with the asymmetric and symmetric stretching of the $\mathrm{CH}$ groups, while at 962 $\mathrm{cm}^{-1}$ it is assigned to the trans vibration of the $-\mathrm{CH}=\mathrm{CH}$ group (da Silva et al., 2017). In the case of beeswax, the peak assigned at $2913 \mathrm{~cm}^{-1}$ is associated with the asymmetrical stretching of the $\mathrm{CH}$ groups, and the one at $2843 \mathrm{~cm}^{-1}$ is related to the symmetrical stretching characteristic of alkane chains. At $1735 \mathrm{~cm}-1$ the stretching of the ester and free fatty acids $\mathrm{C}=\mathrm{O}$ was observed, at $1463 \mathrm{~cm}-1$ the $\mathrm{CH} 2$ deformation of the hydrocarbons, and at $1170 \mathrm{~cm}-1$ the ester $\mathrm{C}-\mathrm{O}$ vibration. Furthermore, between 710 and $730 \mathrm{~cm}^{-1}$ a characteristic vibration of the $\mathrm{CH}_{2}$ group associated with long hydrocarbon chains was registered, corroborating the analysis of Svečnjak et al. (2015).

Analysing the particles spectra $(0.0,0.5,1.0$ and $3.0 \%)$ it is perceptible the presence of the characteristic beeswax peaks at 1733
( $\mathrm{C}=\mathrm{O}$ bonds of esters and free fatty acids), 1463 ( $\mathrm{CH} 2$ of hydrocarbons), 1168 (C-O of esters) and $721 \mathrm{~cm}-1$ ( $\mathrm{CH}_{2}$ of long hydrocarbon chains). In addition to these features, the most characteristic peak of Tween 80 , related to the ester vibration $(1112 \mathrm{~cm}-1)$ is identified in the particle's spectra containing this component $(0.5,1.0$ and $3.0 \%)$, with a tendency to increase slightly as the content increases. The presence of $\beta$-carotene is detected by the peak associated with the trans vibration of the $-\mathrm{CH}=\mathrm{CH}$ group $\left(954 \mathrm{~cm}^{-1}\right)$, presence in all particle's spectra. Thus, SLPs composition reflects the presence of the used raw materials. In addition, the effect of the emulsifier concentration increase was confirmed by the intensification of the peak $1112 \mathrm{~cm}-1$.

\subsection{Food colouring}

Fig. 4 presents all the prepared mixtures, namely the ones using $\beta$-carotene alone (first column), and the ones using the produced microparticles (comprising 0, 0.5, 1 , and $3 \%$ of Tween 80; subsequent columns). Different $\beta$-carotene contents were tested, $1.25,5$ and $10 \mathrm{mg}$ per $25 \mathrm{~g}$ of mayonnaise, which are represented by each line. Since microparticles have the same $\beta$-carotene content, the samples placed in the same line of Fig. 4 correspond to both constant $\beta$-carotene and particle's contents. According to these results it was possible to verify that the mixture prepared with the non-encapsulated $\beta$-carotene gives rises to samples with poor dispersibility and a non-attractive colour, too far from the desired yellow hue. This result can be explained by the fact that pure $\beta$-carotene has a hydrophobic character, leading to a heterogeneous distribution within the product. Concerning the samples added with the produced SLPs, the formulations with higher Tween 80 content were the ones leading to a more homogeneous appearance. The differences noticed on the texture of the samples with $1.25,5$ and $10 \mathrm{mg}$ of $\beta$-carotene $/ 25 \mathrm{~g}$ of commercial mayonnaise (formulations using a Tween content of $3 \%$ ), can be attributed to the higher emulsifier content that have favoured the dispersibility of the particles resulting in a more fluid product (lower viscosity). This result is in agreement with the findings of Panchal et al. (2021) regarding the better distribution of fat globules in butters when Tween 80 is used as emulsifier. In addition, the improved dispersibility allows a better distribution of the SLPs on the final product, thus conferring a more homogeneous and intense colour, as SLPs

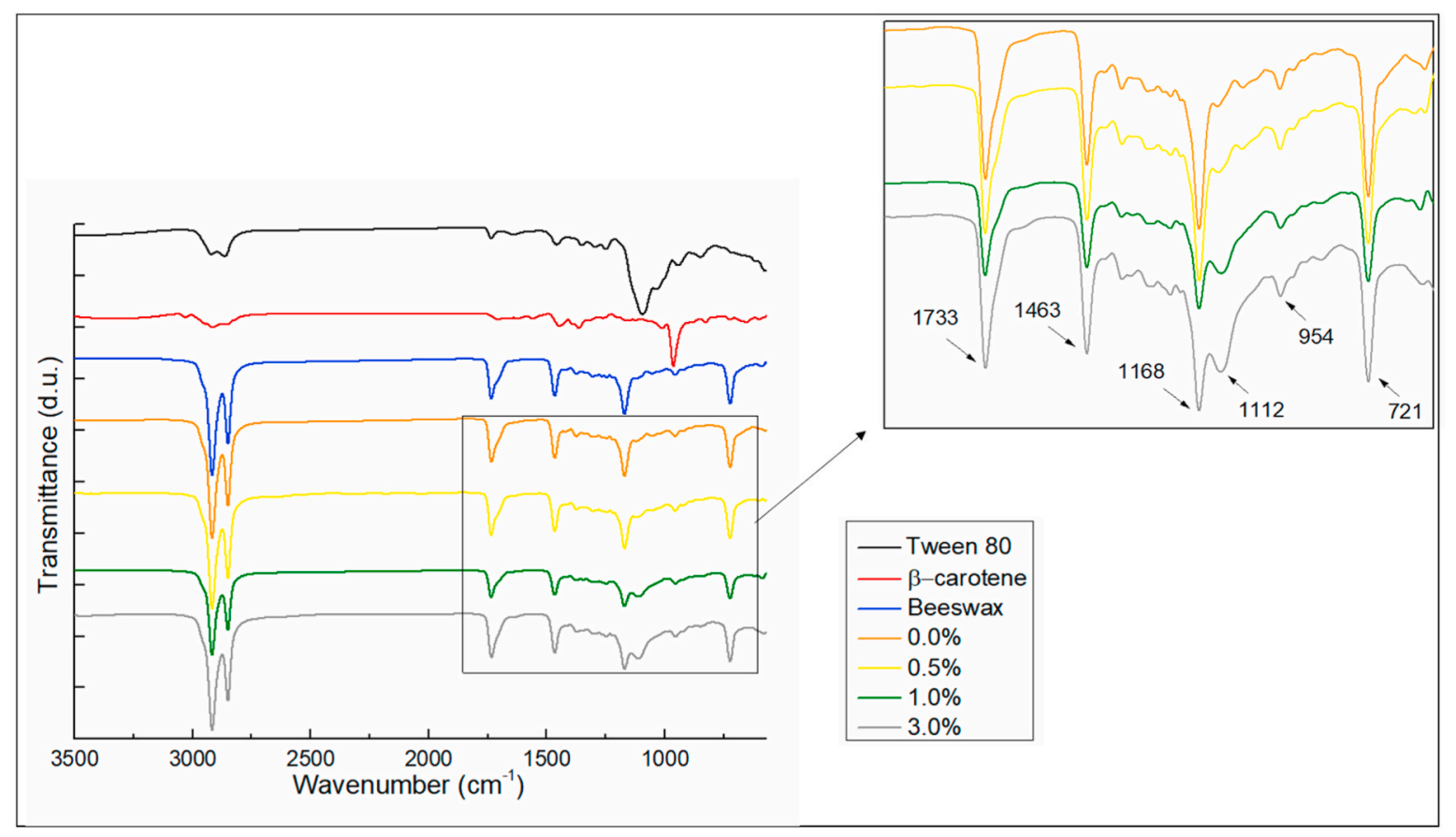

Fig. 3. FTIR spectra of base materials (Tween $80, \beta$-carotene and beeswax) and produced particles $(0.0 ; 0.5 ; 1.0$, and $3 \%$ Tween 80 ). 


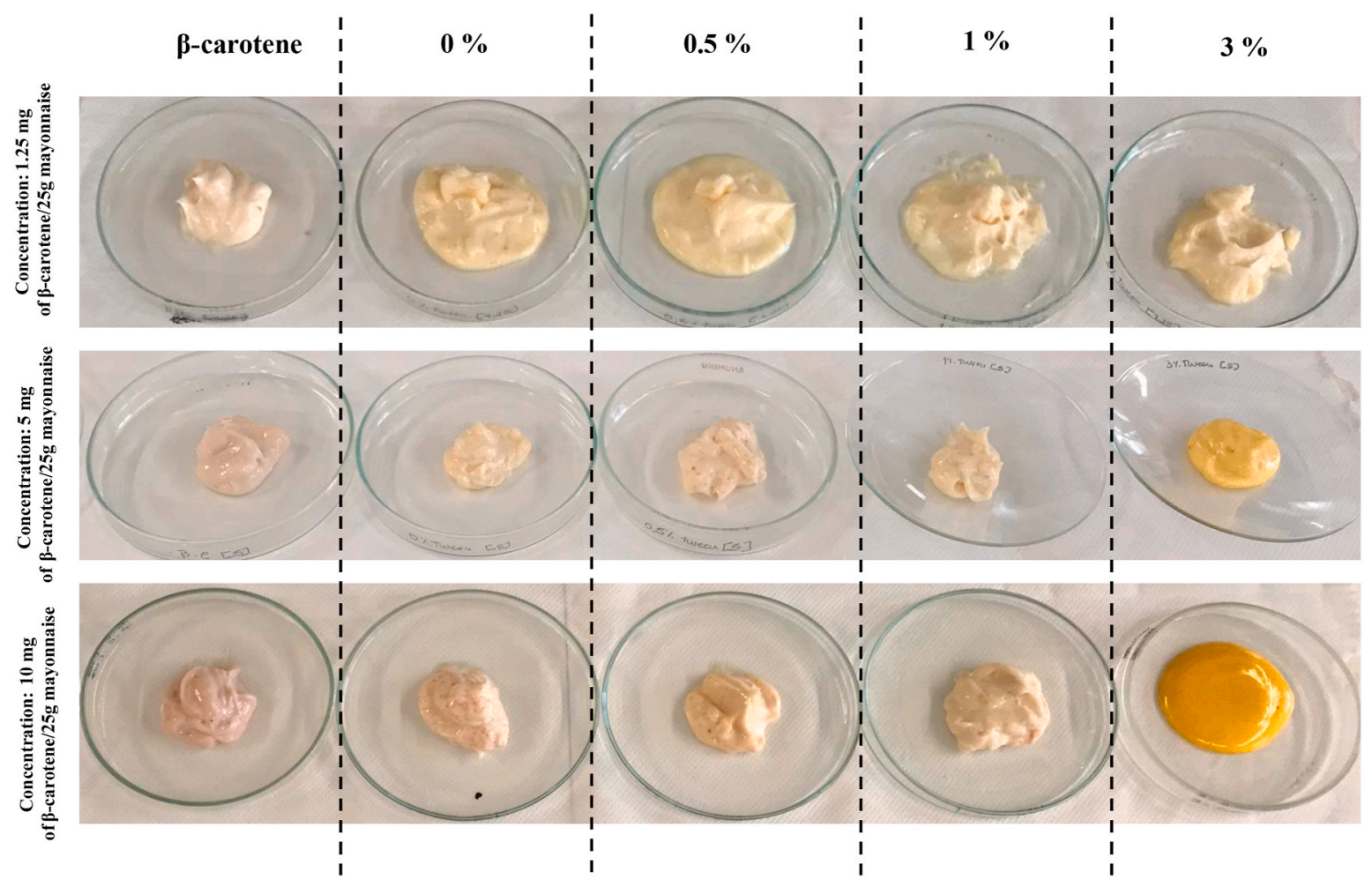

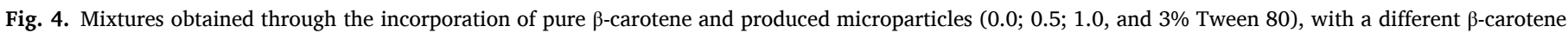
concentration.

(and thus $\beta$-carotene) content increased. In view of these results (visual inspection), the sample prepared with $3 \%$ Tween 80 and using $5 \mathrm{mg}$ of $\beta$-carotene $/ 25 \mathrm{~g}$ of commercial mayonnaise, was chosen to proceed with the evaluation studies along time, immediately after the addition of the ingredient (T0) and after 15 days (T15), under storage at $6{ }^{\circ} \mathrm{C}$.

Considering the importance of the external appearance of food products, and taking into account the recommended storage time for this mayonnaise after opening the bottle, the colour parameters, namely $L^{*}$ (brightness), $a^{*}$ (red colour intensity) and $b^{*}$ (yellow colour intensity), were evaluated in the control sample (commercial mayonnaise without any addition), and in the added mayonnaise samples as previously described (sample with Tween 80 content of $3 \%$ and $5 \mathrm{mg}$ of $\beta$-carotene/ $25 \mathrm{~g}$ of commercial mayonnaise). The colour measurements for $\mathrm{T} 0$ and $\mathrm{T} 15$ are shown in Table 1.

The measurements performed immediately after mixing the particles with the mayonnaise (T0) revealed a statistically significant difference $(p<0.05)$, for all the evaluated colour parameters $\left(L^{*}, a^{*}, b^{*}\right)$, compared with the control sample (commercial mayonnaise). Visually, the obtained mixture showed a yellow hue, with values of $90.8 \pm 0.5$ for parameter $L^{*}$ and $5.1 \pm 0.2$ and $80.7 \pm 0.6$, respectively, for parameters $a^{*}$ and $b^{*}$. The control sample showed $L^{*}, a^{*}$ and $b^{*}$ values of $98.8 \pm 0.6$, $-2.6 \pm 0.2$, and $23.1 \pm 0.9$, respectively. After 15 days under storage, the colour difference between the control sample $\left(L^{*}=97.7 \pm 1.5 ; a^{*}=\right.$ $-1.7 \pm 0.2$ and $\left.b^{*}=26.1 \pm 0,8\right)$ and the mixture $\left(L^{*}=91.0 \pm 0.7 ; a^{*}=\right.$
$15.9 \pm 0.2$ and $b^{*}=81.1 \pm 0.2$ ), continue to present a significant difference in all parameters, as expected by the authors.

Comparing the shelf-life times, the control sample at the end of the evaluated period showed changes in the analysed parameters, being the parameter $L^{*}$ the only on that that was maintained $(98 \pm 2)$. On the other hand, the parameters $a^{*}(-1.7 \pm 0.2)$ and $b^{*}(26.1 \pm 0.8)$ evidenced a statistically significant increase, which was translated into a slight tone change. Concerning the developed mixture (mayonnaise added with $\beta$-carotene loaded lipid particles), the parameter $L^{*}(91.0 \pm$ $0.7)$ did not show significant changes, as well as $b^{*}$ parameter $(81.1 \pm$ $0.2)$; with $a^{*}(15.9 \pm 0.2)$ being the only parameter where a slight increase was observed. This variation can be associated with $\beta$-carotene release along the storage time driven by the rearrangement of the fat crystals inside the particles. In this case, the released $\beta$-carotene can undergo oxidative degradation upon contact with the external medium. This effect was also depicted by Qian and co-workers (Qian et al., 2013) when analysing the impact of the lipid nanoparticle's physical state on $\beta$-carotene degradation. However, the slight hue variation detected on the studied mayonnaise sample evidences a weak effect of this phenomena within the studied time frame (15 days). For a better perception of the shades of the control sample and the developed mixture, the respective CIE values were converted to RGB using a program (<http://www.easyrgb.com/en/convert.php $>$ ) (Table 1).

Table 1

Colour parameters $\left(L^{*}, a^{*}, b^{*}\right)$ measured in the control mayonnaise sample and the mixture obtained by adding colouring microparticles. Values are presented as mean \pm standard deviation.

\begin{tabular}{|c|c|c|c|c|c|c|c|c|}
\hline & Control T0 days & Colour RGB & $\begin{array}{l}\text { Control } \\
\text { T15 days }\end{array}$ & Colour RGB & $\begin{array}{l}\text { Mixture } \\
\text { T0 days }\end{array}$ & Colour RGB & $\begin{array}{l}\text { Mixture } \\
\text { T15 days }\end{array}$ & Colour RGB \\
\hline$L^{*}$ & $98.8 \pm 0.6^{\mathrm{b}}$ & & $97.7 \pm 0.5^{\mathrm{b}}$ & & $90.8 \pm 0.5^{\mathrm{a}}$ & & $91.0 \pm 0.7^{\mathrm{a}}$ & \\
\hline$a^{*}$ & $-2.6 \pm 0.2^{\mathrm{a}}$ & & $-1.7 \pm 0.2^{\mathrm{b}}$ & & $15.1 \pm 0.2^{\mathrm{c}}$ & & $15.9 \pm 0.2^{\mathrm{d}}$ & \\
\hline
\end{tabular}

In each line, different letters signify significant differences between the colouring $(p<0.05)$. 


\subsection{Evaluation of the nutritional value of the coloured mayonnaise}

The results regarding the evaluation of the nutritional value (fat, protein, ash, carbohydrates, free sugars and energy), and chemical composition (fatty acids), of the control sample (mayonnaise without any addition), and the developed coloured mixture are shown in Table 2. This parameter allowed to evaluate the effects of this colouring ingredient on the nutritional profile of the selected food product. Regarding the nutritional value, at $\mathrm{T} 0$, the control sample and the coloured mixture did not reveal statistically significant differences $(p>0.05)$ in any of the analysed parameters. The same was verified after 15 days (T15) under storage at $6{ }^{\circ} \mathrm{C}$, where no changes have occurred in the nutritional value.

Taking into account the obtained results, it was evident that the macronutrients present at higher amount were fats, showing values ranging from $81.4 \pm 0.4$ to $82 \pm 2 \mathrm{~g} / 100 \mathrm{~g}$; followed by carbohydrate content ( $15 \pm 1$ to $16.8 \pm 0.5 \mathrm{~g} / 100 \mathrm{~g})$. The protein content was low (within the range from $0.95 \pm 0.07$ to $1.4 \pm 0.1 \mathrm{~g} / 100 \mathrm{~g}$ ), as well as the ash content $(0.916 \pm 0.005$ to $0.92 \pm 0.01 \mathrm{~g} / 100 \mathrm{~g})$. Regarding carbohydrates, values between $15 \pm 1$ and $16.8 \pm 0.5 \mathrm{~g} / 100 \mathrm{~g}$ were determined, with sucrose presenting a concentration between $2.05 \pm 0.01$ and $2.10 \pm 0.01 \mathrm{~g} / 100 \mathrm{~g}$. In general, the energy value was comprised between $803 \pm 3$ and $808 \pm 8 \mathrm{Kcal} / 100 \mathrm{~g}$.

Several studies have been already carried concerning the determination of the nutritional composition of mayonnaise, as well as of mayonnaise incorporated with colouring ingredients, particularly anthocyanins as mentioned by Gorji et al. (2016). However, no studies were found dealing with the incorporation of $\beta$-carotene colorant microparticles.

\section{Table 2}

Nutritional (fat, proteins, ash, carbohydrates, sucrose, energy) and chemical composition (fatty acids) of the control mayonnaise sample and the mixture obtained by adding the colouring microparticles ( $\mathrm{g} / 100 \mathrm{~g}$ fresh mass). Values are presented as mean \pm standard deviation.

\begin{tabular}{|c|c|c|c|c|}
\hline & $\begin{array}{l}\text { Control } \\
\text { T0 days }\end{array}$ & $\begin{array}{l}\text { Control } \\
\text { T15 days }\end{array}$ & $\begin{array}{l}\text { Mixture } \\
\text { T0 days }\end{array}$ & $\begin{array}{l}\text { Mixture } \\
\text { T15 days }\end{array}$ \\
\hline Fat $(g / 100 g)$ & $81.6 \pm 0.2^{\mathrm{a}}$ & $81.4 \pm 0.4^{\mathrm{a}}$ & $82 \pm 2^{\mathrm{a}}$ & $82 \pm 2^{\mathrm{a}}$ \\
\hline Proteins $(\mathrm{g} / \mathbf{1 0 0 g})$ & $\begin{array}{l}0.98 \pm \\
0.01^{\mathrm{a}}\end{array}$ & $\begin{array}{l}0.95 \pm \\
0.07^{\mathrm{a}}\end{array}$ & $\begin{array}{l}0.99 \pm \\
0.02^{\mathrm{a}}\end{array}$ & $0.98 \pm 0.3^{\mathrm{a}}$ \\
\hline Ash (g/100g) & $\begin{array}{l}0.918 \pm \\
0.001^{\mathrm{a}}\end{array}$ & $\begin{array}{l}0.916 \pm \\
0.005^{\mathrm{a}}\end{array}$ & $\begin{array}{l}0.917 \pm \\
0003^{\mathrm{a}}\end{array}$ & $0.92 \pm 0.01^{\mathrm{a}}$ \\
\hline $\begin{array}{l}\text { Carbohydrates (g/ } \\
\text { 100g) }\end{array}$ & $16.3 \pm 0.1^{\mathrm{a}}$ & $16.4 \pm 0.5^{\mathrm{a}}$ & $15.6 \pm 2^{\mathrm{a}}$ & $15 \pm 1^{\mathrm{a}}$ \\
\hline Sucrose $(g / 100 g)$ & $\begin{array}{l}2.20 \pm \\
0.11^{\mathrm{a}}\end{array}$ & $\begin{array}{l}2.17 \pm \\
0.08^{\mathrm{a}}\end{array}$ & $\begin{array}{l}2.05 \pm \\
0.10^{\mathrm{a}}\end{array}$ & $2.05 \pm 0.08^{\mathrm{a}}$ \\
\hline Energy (kcal/100g) & $\begin{array}{l}804.3 \pm \\
0.8^{\mathrm{a}}\end{array}$ & $803 \pm 2^{\mathrm{a}}$ & $807 \pm 9^{a}$ & $808 \pm 8^{a}$ \\
\hline Energy (kJ/100g) & $3369 \pm 3^{\mathrm{a}}$ & $3365 \pm 8^{\mathrm{a}}$ & $3382 \pm 39^{\mathrm{a}}$ & $3369 \pm 3^{\mathrm{a}}$ \\
\hline C16:0 & $\begin{array}{l}4.813 \pm \\
0.004^{\mathrm{a}}\end{array}$ & $\begin{array}{l}4.81 \pm \\
0.01^{\mathrm{a}}\end{array}$ & $\begin{array}{l}4.89 \pm \\
0.04^{\mathrm{a}}\end{array}$ & $\begin{array}{l}4.860 \pm \\
0.004^{\mathrm{a}}\end{array}$ \\
\hline C18:0 & $\begin{array}{l}1.97 \pm \\
0.01^{\mathrm{a}}\end{array}$ & $\begin{array}{l}1.969 \pm \\
0.001^{\mathrm{a}}\end{array}$ & $\begin{array}{l}1.96 \pm \\
0.03^{\mathrm{a}}\end{array}$ & $1.95 \pm 0.04^{\mathrm{a}}$ \\
\hline C18:1n9 & $\begin{array}{l}61.68 \pm \\
0.03^{\mathrm{a}}\end{array}$ & $\begin{array}{l}61.66 \pm \\
0.001^{\mathrm{a}}\end{array}$ & $61.9 \pm 0.1^{\mathrm{b}}$ & $\begin{array}{l}62.09 \pm \\
0.08^{\mathrm{b}}\end{array}$ \\
\hline C18:2n6 & $\begin{array}{l}20.28 \pm \\
0.01^{b}\end{array}$ & $\begin{array}{l}20.35 \pm \\
0.07^{\mathrm{b}}\end{array}$ & $\begin{array}{l}19.86 \pm \\
0.07^{\mathrm{a}}\end{array}$ & $\begin{array}{l}19.86 \pm \\
0.01^{\mathrm{a}}\end{array}$ \\
\hline C18:3n3 & $\begin{array}{l}8.27 \pm \\
0.01^{\mathrm{a}}\end{array}$ & $\begin{array}{l}8.27 \pm \\
0.02^{\mathrm{a}}\end{array}$ & $8.4 \pm 0.2^{\mathrm{a}}$ & $8.30 \pm 0.01^{a}$ \\
\hline C20:1 & $\begin{array}{l}1.037 \pm \\
0.001^{\mathrm{a}}\end{array}$ & $\begin{array}{l}1.039 \pm \\
0.001^{\mathrm{a}}\end{array}$ & $\begin{array}{l}1.04 \pm \\
0.02^{\mathrm{a}}\end{array}$ & $1.04 \pm 0.02^{\mathrm{a}}$ \\
\hline SFA & $\begin{array}{l}8.04 \pm \\
0.02^{\mathrm{a}}\end{array}$ & $\begin{array}{l}8.025 \pm \\
0.001^{\mathrm{a}}\end{array}$ & $\begin{array}{l}8.05 \pm \\
0.01^{\mathrm{a}}\end{array}$ & $8.00 \pm 0.01^{\mathrm{a}}$ \\
\hline MUFA & $\begin{array}{l}63.27 \pm \\
0.03^{\mathrm{a}}\end{array}$ & $63.2 \pm 0.1^{\mathrm{a}}$ & $63.6 \pm 0.1^{\mathrm{b}}$ & $63.7 \pm 0.1^{\mathrm{b}}$ \\
\hline PUFA & $\begin{array}{l}28.69 \pm \\
0.02^{\mathrm{b}}\end{array}$ & $28.7 \pm 0.1^{\mathrm{b}}$ & $28.4 \pm 0.1^{\mathrm{a}}$ & $\begin{array}{l}28.328 \pm \\
0.001^{\mathrm{a}}\end{array}$ \\
\hline
\end{tabular}

In each line, different letters signify significant differences between the nutritional parameter evaluated $(p<0.05)$. C16:0 palmitic acid; C18:0 stearic acid; C18:1n9 oleic acid; C18:2n6 linoleic acid; C18:3n3 $\alpha$-linolenic acid; C20:1 eicosanoic acid; SFA: saturated fatty acids; MUFA: monounsaturated fatty acids; PUFA: polyunsaturated fatty acids.
Rashed et al. (2017) studied the nutritional composition of several commercial mayonnaise samples, using official methods of analysis (AOAC). The results showed values in agreement with those obtained in the present study regarding the protein content $(1.09 \pm 0.1 \mathrm{~g} / 100 \mathrm{~g})$. However, the remaining nutrients showed some discrepancy. Regarding carbohydrates and ash, they found higher values $(37.88 \pm 9.06 \mathrm{~g} / 100 \mathrm{~g}$ and $1.57 \pm 0.13 \mathrm{~g} / 100 \mathrm{~g}$, respectively), and lower ones for fat (30.76 \pm $9.12 \mathrm{~g} / 100 \mathrm{~g}$ ). The same is true for free sugars detected in commercial mayonnaise samples, where some of the most representative are fructose $(1.40 \pm 0.2 \mathrm{~g} / 100 \mathrm{~g})$, glucose $(1.71 \pm 0.31 \mathrm{~g} / 100 \mathrm{~g})$, and maltose $(0.18$ $\pm 0.18 \mathrm{~g} / 100 \mathrm{~g})$. The primary free sugar was sucrose $(5.58 \pm 1.23 \mathrm{~g} / 100$ $\mathrm{g}$ ), in accordance with the present study.

The Institute of Metabolism and Nutrition (IMEN, 2011) also launched a technical-scientific dossier, where it exposes the nutritional composition of several commercial mayonnaise samples provided by 3 laboratories recognised by the Brazilian Network of Analytical Health Laboratories (REBLAS). The results revealed a nutritional composition rich in fat $(32.89 \pm 0.56 \mathrm{~g} / 100 \mathrm{~g})$, and low in proteins $(0.73 \pm 0.12$ $\mathrm{g} / 100 \mathrm{~g})$, and carbohydrates $(6.50 \pm 0.79 \mathrm{~g} / 100 \mathrm{~g})$. The caloric content was $325.46 \pm 4.02 \mathrm{KCal} / 100 \mathrm{~g}$.

The observed discrepancies can be derived from the use of different mayonnaise formulations, which may include different ingredients and preparation procedures.

The individual fatty acid composition (with values higher than $1 \%$ ), as well as the content of saturated, monounsaturated and polyunsaturated fatty acids of the control mayonnaise sample, and the developed coloured mixture, are shown in Table 2.

This analysis allowed the identification of seventeen fatty acids, with oleic acid (C18:1n9) and linoleic acid (C18:2n6) standing out as the major one in all studied samples. These were the only molecules where a statistically significant change $(p<0.05)$ between the analysed samples (control and coloured mixture) was observed. This can be explained due to the fatty acids profile of the used lipid, beeswax, which according to other previous studies showed the presence of palmitic, palmitoleic, oleic, linoleic, linolenic and tetracosanoic acids (Buchwald et al., 2009).

Regarding the composition in saturated fatty acids (SFA), the concentrations obtained varied between $8.00 \pm 0.01$ and $8.05 \pm 0.01 \%$, showing no significant differences $(p>0.05)$ between the control sample and the coloured mixture, both at times 0 and 15 days. The same did not happen with monounsaturated (MUFA) and polyunsaturated (PUFA) fatty acids, where the obtained content was slightly different, but significant $(p<0.05)$. Taking into account the storage time, it was evident that in none of the cases (control and coloured mixture) a change in the fatty acid composition, due to time, was observed.

Other authors have studied the fatty acid profile of mayonnaises, namely in the work of Rashed et al. (2017) several mayonnaise samples have been analysed. The results showed that the major fatty acid was palmitic acid (C16:0), with values of $10.02 \mathrm{~g} / 100 \mathrm{~g}$, and that a high concentration of saturated (SFA; $12.49 \pm 6.85 \mathrm{~g} / 100 \mathrm{~g}$ ) and polyunsaturated (PUFA; $10.38 \pm 3.22 \mathrm{~g} / 100 \mathrm{~g}$ ) fatty acids was present. The Metabolism and Nutrition Institute (IMEN, 2011), also revealed the nutritional composition of several commercial mayonnaise samples, namely concerning the concentration in saturated, monounsaturated and polyunsaturated fatty acids, the latter being shown as the major compounds (17.9 g/100 g).

The achieved discrepancies can be justified in light of the compositional diversity of mayonnaise formulations existing in the market, and used in the several analysed works.

\section{Conclusions}

In this work hot melt dispersion technique was successfully used to produce $\beta$-carotene loaded lipid particles that were further tested as mayonnaise colorant agents. The used methodology revealed to be an effective strategy to modulate the size of the microparticles, as well as the dispersibility characteristics. Particularly, it was observed that the 
particle size diminished as the emulsifier content increased, fact accompanied by a dispersibility improvement. The morphological analysis of the particles, namely by SEM, indicated a spherical shape for all produced formulations, and that agglomeration was less pronounced when a higher content of emulsifier was used. This is an advantage of the used productive process, hot melt dispersion technique, e.g. in comparison with spray-cooling, where no emulsifier is typically used.

The sample showing the best colour and dispersibility characteristics, resembling as much as possible the appearance of a homemade mayonnaise, as it might be more attractive for consumers, was selected (sample with a Tween 80 content of $3 \%$ and $5 \mathrm{mg}$ of $\beta$-carotene/25 $\mathrm{g}$ of commercial mayonnaise). The colour parameters were analysed, and a notorious statistically significant difference was obtained between the control and the chosen coloured sample, in the measured hue. However, comparing the coloured sample, over the storage period of 15 days, it was clear that the parameters $L^{*}$ and $b$ * did not show statistically significant differences with time. In contrast, the parameter $a^{*}$ showed a significant difference with time indicating an increase of the red colour intensity.

Regarding the nutritional evaluation, the results pointed out no statistically significant differences for most of the evaluated parameters, except for the fatty acid profile, which revealed a statistically significant increase of the oleic acid content after incorporation of the colorant microparticles, fact associated with the used beeswax fatty acids composition. These results are interesting results in view that oleic acid is responsible for several biochemical processes occurring in the body, being associated with the control of risk factors in some clinical conditions. Also, the applied techniques revealed a very satisfactory final result, not only concerning the obtainment of the desired colour but also due to its preservation throughout the storage time. Thus, this study is a contribution to promote the applicability of natural colouring ingredients in the food industry, bringing not only scientific development, but also innovation to the food sector.

\section{CRediT authorship contribution statement}

Amarilis Santos de Carvalho: Methodology, Investigation, Writing. Stephany Cunha de Rezende: Methodology, Investigation, Writing. Cristina Caleja: Conceptualization, Methodology, Investigation, Validation, Writing. Eliana Pereira: Conceptualization, Methodology, Investigation, Validation, Writing. Lillian Barros: Conceptualization, Methodology, Writing - review \& editing. Isabel Fernandes: Methodology, Investigation. Yaidelin A. Manrique: Methodology, Investigation. Odinei Hess Gonçalves: Methodology, Writing - review \& editing. Isabel C.F.R. Ferreira: Conceptualization, Methodology. Maria Filomena Barreiro: Conceptualization, Methodology, Writing - review \& editing.

\section{Declaration of competing interest}

The authors declare that they have no known competing financial interests or personal relationships that could have appeared to influence the work reported in this paper.

\section{Acknowledgements}

The authors are grateful to the Foundation for Science and Technology (FCT, Portugal) and FEDER under Programme PT2020 for financial support to CIMO (UIDB/00690/2020), and to UIDB/50020/ 2020 of the Associate Laboratory LSRE-LCM - funded by national funds through FCT/MCTES (PIDDAC); national funding by FCT, PI, through the institutional scientific employment program-contract for L. Barros's and I. Fernandes contract; to the project AllNat for the contract of C. Caleja (Project AllNat POCI-01-0145-FEDER-030463), the Valor Natural project for the contract of E. Pereira (Mobilized Project Norte-01-0247FEDER-024479), and FCT for the PhD research grant SFRH/BD/
$147326 / 2019$ (S.C. Rezende). This work is also funded by the European Regional Development Fund (ERDF) through the Regional Operational Program North 2020, within the scope of Project Mobilizador Norte-010247-FEDER-024479: ValorNatural $₫$; and to FEDER-Interreg EspañaPortugal programme for financial support through the project TRANSCoLAB 0612_TRANS_CO_LAB_2_P.

\section{References}

AOAC. (2016). AOAC official methods of analysis (20th ed. ed.). AOAC INTERNATIONAL. Azeredo. (2005). Encapsulação: Aplicação à Tecnologia de Alimentos. Alimentos e Nutrição, 16, 89-97.

Ban, C., Jo, M., Lim, S., \& Choi, Y. J. (2018). Control of the gastrointestinal digestion of solid lipid nanoparticles using PEGylated emulsifiers. Food Chemistry, 239, 442-452.

Ban, C., Jo, M., Park, Y. H., Kim, J. H., Han, J. Y., Lee, K. W., Kweon, D.-H., \& Choi, Y. J. (2020). Enhancing the oral bioavailability of curcumin using solid lipid nanoparticles. Food Chemistry, 302, 125328.

Barros, L., Pereira, E., Calhelha, R. C., Dueñas, M., Carvalho, A. M., Santos-Buelga, C., \& Ferreira, I. C. F. R. (2013). Bioactivity and chemical characterisation in hydrophilic and lipophilic compounds of Chenopodium ambrosioides L. Journal of Functional Foods, 5, 1732-1740.

de Boer, F. Y., Imhof, A., \& Velikov, K. P. (2019). Encapsulation of colorants by natural, polymers for food applications. Coloration Technology, 135(1), 183-194.

Buchwald, R., Breed, M. D., Bjostad, L., Hibbard, B. E., \& GreEnberg, A. R. (2009). The role of fatty acids in the mechanical properties of beeswax. Apidologie, 40, 585-594.

Caleja, C., Barros, L., Antonio, A. L., Carocho, M., Oliveira, M. B. P. P., \& Ferreira, I. C. F. R. (2016). Fortification of yogurts with different antioxidant preservatives: A comparative study between natural and synthetic additives. Food Chemistry, 210, 262-268.

Campos, J. R., Severino, P., Santini, A., Silva, A. M., Shegokar, R., Souto, S. B., \& Souto, E. B. (2020). Chapter 1 - solid lipid nanoparticles (SLN): Prediction of toxicity, metabolism, fate and physicochemical properties. In Nanopharmaceuticals: Volume 1: Expectations and realities of multifunctional drug delivery systems (pp. 1-15). Elsevier.

Carocho, M., Filomena Barreiro, M., Morales, P., Isabel, C.Ferreira, F. R., ... (2014). "Adding molecules to food, pros and cons: A review on synthetic and natural food additives: Adding molecules to food, pros and cons. Comprehensive Reviews in Food Science and Food Safety, 13, 377-399.

Costa, L. C., Louchard, B. O., Rodrigues Neto, E. M., Giffony, P. S., Campos, F. M. T., \& Araujo, T. G. (2020). Development and characterization of kojic acid and carnaúba wax-based solid lipid microparticles. Journal of Young Pharmacists, 12(4), 309-313.

EFSA. (2012). Scientific Opinion on the re-evaluation of mixed carotenes (E 160a (i)) and (E 160a (ii)) as a food additive. EFSA Journal, 10(3), 1-67.

Eldem, T., Speiser, P., \& Altorfer, H. (1991). Polymorphic behavior of sprayed lipid micropellets and its evaluation by differential scanning calorimetry and scanning electron microscopy. Pharmaceutical Research, 8(2), 178-184.

Ganesan, P., \& Narayanasamy, D. (2017). Lipid nanoparticles: Different preparation techniques, characterisation, hurdles, and strategies for the production of solid lipid nanoparticles and nanostructured lipid carriers for oral drug delivery. Sustainable Chemistry and Pharmacy, 6, 37-56.

Ghanbarzadeh, B., \& Keivani, F. (2019). Chapter six - encapsulation of food ingredients by solid lipid nanoparticles (SLNs). Lipid-based nanostructures for food encapsulation purposes (pp. 179-216). Elsevier Inc.

Gordillo-Galeano, A., \& Mora-Huertas, C. E. (2018). Solid lipid nanoparticles and nanostructured lipid carriers: A review emphasising on particle structure and drug release. European Journal of Pharmaceutics and Biopharmaceutics, 133, 285-308.

Gorji, S. G., Smyth, H. E., Sharma, M., \& Fitzgerald, M. (2016). Lipid oxidation in mayonnaise and the role of natural antioxidants: A review. Trends in Food Science \& Technology, 56, 88-102.

Gowda, D. V., \& Shivakumar, H. G. (2007). Preparation and evaluation of waxes/fat microspheres loaded with lithium carbonate for controlled release. Indian Journal of Pharmaceutical, 251-256.

IMEN. (2011). Perfil nutricional da maionese industrializada a partir de Laudos técnicos. http://www.nutricaoclinica.com.br/_n1/pdfs/dossie_tecnico_cientifico_perfil_nutric ional_maionese_industrializada.pdf.

Ishimoto, K., Miki, S., Ohno, A., Nakamura, Y., Otani, S., Nakamura, M., \& Nakagawa, S. (2019). b-Carotene solid dispersion prepared by hot-melt technology improves its solubility in water. Journal of Food Science \& Technology, 56(7), 3540-3546.

Kamble, R., Maheshwari, M., Paradkar, A., \& Kadam, S. (2004). Melt solidification technique: Incorporation of higher wax content in ibuprofen beads. AAPS PharmSciTech, 5(4), 1-9.

Kheradmandnia, S., Vasheghani-Farahani, E., Nosrati, M., \& Atyabi, F. (2010). Preparation and characterisation of ketoprofen-loaded solid lipid nanoparticles made from beeswax and carnauba wax. Nanomedicine: Nanotechnology, Biology and Medicine, 6, 753-759.

Kohno, Y., et al. (2016). Fixation and stability enhancement of beta-carotene by organomodified mesoporous silica. Microporous and Mesoporous Materials, 220, 1-6.

Krinsky, N. I., \& Johnson, E. J. (2005). Carotenoid actions and their relation to Health and disease. Molecular Aspects of Medicine, 26, 459-516.

de Lima, J. G., Brito-Oliveira, T. C., \& Pinho, S. C. (2016). Characterization and evaluation of sensory acceptability of ice creams incorporated with beta-carotene encapsulated in solid lipid microparticles. Food Science and Technology, 36(4), 664-671. 
Lim, J. Y., \& Wang, X.-D. (2020). Mechanistic understanding of $\beta$-cryptoxanthin and lycopene in cancer prevention in animal models. BBA - Molecular and Cell Biology of Lipids. https://doi.org/10.1016/j.bbalip.2020.158652

Liu, Y., Gu, J., Zhang, J., Yu, F., Wang, J., Nie, N., \& Li, W. (2015). LiFePO4 nanoparticles growth with preferential (010) face modulated by Tween-80. RSC Advances, 5, 9745-9751.

Mehrad, B., Ravanfar, R., Licker, J., \& Regenstein, J. M. (2018). Enhancing the physicochemical stability of $\beta$-carotene solid lipid nanoparticle (SLNP) using whey protein isolate. Food Research International, 105, 962-969.

Milanovic, J., Levic, S., Manojlovic, V., Nedovic, V., \& Bugarski, B. (2011). Carnauba wax microparticles produced by melt dispersion technique. Chemical Papers, 65(2), 213-220.

Milanović, J., S, G. I., Gavrilović, M., Milosavljević, M., \& Bugarski, B. (2017). Blend of natural waxes as a matrix for aroma encapsulation. Facta Universitatis, 15(2), 103-111.

Msagati, T. A. M. (Ed.). (2013). The chemistry of food additives and preservatives. Oxford; Ames, Iowa: Wiley-Blackwell.

Panchal, B., Truong, T., Prakash, S., Bansal, N., \& Bhandari, B. (2021). Influence of fat globule size, emulsifiers, and cream-aging on microstructure and physical properties of butter. International Dairy Journal, 117, 105003.

Paradkar, A. R., Maheshwari, M., Ketkar, A. R., \& Chauhan, B. (2003). Preparation and evaluation of ibuprofen beads by melt solidification technique. International Journal of Pharmaceutics, 255, 33-42.

Qian, C., Decker, E. A., Xiao, H., \& McClements, D. J. (2013). Impact of lipid nanoparticle physical state on particle aggregation and $\beta$-carotene degradation: Potential limitations of solid lipid nanoparticles. Food Research International, 52, 342-349.
Rashed, A., Khalid, N. M., Noh, M. F. M., \& Rahman, N. I. (2017). The nutritional composition of mayonnaise and salad dressing in the Malaysian market. Sains Malaysiana, 46, 139-147.

Salminen, H., Stubler, A.-S., \& Weiss, J. (2020). Preparation, characterization, and physical stability of cocoa butter and tristearin nanoparticles containing $\beta$-carotene. European Food Research and Technology, 246, 599-608.

Santos, V. da S., Ribeiro, A. P. B., \& Santana, M. H. A. (2019). Solid lipid nanoparticles as carriers for lipophilic compounds for applications in foods. Food Research International, 122, 610-626:

Schjoerring-Thyssen, J., Olsen, K., Koehler, K., Jouenne, E., Rousseau, D., \& Larsen, A. M. (2019). Morphology and structure of solid lipid nanoparticles loaded with high concentrations of $\beta$ - carotene. Journal of Agricultural and Food Chemistry, 67, 12273-12282.

Selvakumar, S., Janakiraman, A. B., Michael, M. L., Arthur, M. J., \& Chinnaswamy, A. (2019). Formulation and characterization of $\beta$-carotene loaded solid lipid nanoparticles. Journal of Food Processing and Preservation, 43, Article e14212.

da Silva, H. R. G., Quintella, C. M., \& Meira, M. (2017). Separation and identification of functional groups of molecules responsible for fluorescence of biodiesel using FTIR spectroscopy and principal component analysis. Journal of the Brazilian Chemical Society, 28(12), 2348-2356.

Svečnjak, L., Baranović, G., Vinceković, M., Prđun, S., Bubalo, D., \& Gajger, I. T. (2015). An approach for routine analytical detection of beeswax adulteration using FTIRATR spectroscopy. Journal of Apicultural Science.

Zhong, Q., \& Zhang, L. (2019). Nanoparticles fabricated from bulk solid lipids: Preparation, properties, and potential food applications. Advances in Colloid and Interface Science, 273, 102033. 